\title{
The effect of drugs and stimulants on gastric myoelectrical activity
}

\author{
Krzysztof Jonderko' ${ }^{1}$, Jarosław Kwiecieñ ${ }^{2}$, Anna Kasicka-Jonderkoํㅜ, Magdalena Buschhaus ${ }^{3}$ \\ ${ }^{1}$ Department of Basic Biomedical Science, School of Pharmacy, Sosnowiec, Poland \\ 2Department of Paediatrics, School of Medicine in Zabrze, Medical University of Silesia, Katowice, Poland \\ ${ }^{3}$ Centre for Therapeutic Discovery, Medical Research Council Technology, London, UK
}

Prz Gastroenterol 2014; 9 (3): 130-135

DOI: $10.5114 /$ pg.2014.43573

Key words: drugs, drug adverse effects, electrogastrography, gastric myoelectrical activity, prokinetics.

Address for correspondence: Prof. Krzysztof Jonderko MD, PhD, Department of Basic Biomedical Science, Medical University of Silesia, 3 Kasztanowa St, 41-205 Sosnowiec, Poland, phone: +48 3226998 30, fax: +48 32269 98 33, e-mail: kjonderko@sum.edu.pl

\begin{abstract}
Electrogastrography (EGG) is a non-invasive diagnostic method useful for the registration and analysis of gastric myoelectrical activity. Abnormalities within an electrogastrogram were found to correlate with a number of disorders and symptoms, like functional dyspepsia, diabetic gastroparesis and terminal hepatic or renal failure. The EGG is also a valuable diagnostic method enabling the evaluation of the effect of drugs on gastric myoelectrical activity, which can be intentional, as in the case of prokinetics, or can have an adverse character. Our review focuses on drugs with a proven impact on gastric myoelectrical activity and hence on the electrogastrogram. The paper assembles and discusses the results of investigations dealing with changes in the electrogastrograms evoked by various drugs. Moreover, the mechanisms of the influence on the gastric myoelectrical activity of drugs, curative substances and stimulants are presented.
\end{abstract}

\section{Introduction}

Development of electrogastrography (EGG), and acceptance of this diagnostic method as a reliable tool in clinical practice, has led to great interest in research evaluating gastric myoelectrical activity. A growing body of evidence shows that some of the signs and symptoms of gastric dysfunction correlate well with the results of electrogastrographic recording and analysis of gastric myoelectrical activity (GMA), and have raised the conclusion that EGG can be used as a source of measurable indicators of the severity of gastric dysfunction in a number of diseases such as diabetes, functional dyspepsia, end-stage kidney or liver disease, anorexia or bulimia [1].

Having such a research tool is potentially very valuable, especially when one wants to objectively assess the degree of severity of a disease and/or efficacy of the treatment. Changes in GMA may also cause symptoms identified as side effects of drugs. In such cases, knowledge of the impact of drugs on the electrogastrographic record and the possibility to quantify this effect appear to be important in medical practice. This paper presents the issue of the impact of drugs on GMA, in two aspects of this phenomenon:

- in the case of drugs used with the intention of normalising gastric motility disorders, and

- with drugs used for other indications, whose side effects impact the function and/or gastric motility, demonstrable in electrogastrographic tracing.

In addition, we discuss the impact of popular stimulants on GMA.

\section{Drugs used in gastrointestinal motility disorders and their impact on the electrogastrogram}

One of the most common disorders of gastric motility, causing troublesome subjective symptoms, is abnormal, delayed gastric emptying - also called gastroparesis. Clinical symptoms are mainly pain in the upper abdomen, often described by patients as bloating, feeling of food retention long after meals, avoiding meals of larger volume caused by fears of many hours of postprandial discomfort. This phenomenon is particularly prevalent in patients with long-standing diabetes 
and is typically accompanied by gastric dysrhythmia observed in the EGG study [1].

Another common gastric motility disorder, causing unpleasant subjective symptoms, is impairment in gastric fundus accommodation. Physiologically, food intake causes relaxation of the gastric fundus, which acts as a reservoir. This allows for absorbance of relatively large amounts of food, its storage and pre-mixing, followed by activation of the propulsive motility moving portions of food toward the antrum. Impaired accommodation of the gastric fundus can cause discomfort in the form of early fullness after small amounts of food, with postprandial pain or discomfort in the upper abdomen.

Treatment of gastroparesis mainly uses prokinetic drugs, which include: metoclopramide, domperidone, erythromycin, cisapride and related drugs (mosapride, prucalopride).

1. Metoclopramide is used as a prokinetic drug showing also strong antiemetic action. It functions as an antagonist of dopaminergic receptor D2. Unfortunately, lack of selectivity causes metoclopramide to stimulate receptors present in the central nervous system and can trigger unpleasant side effects in the form of extrapyramidal disorders [2]. Paradoxically, despite its popularity and long-term presence in the market, metoclopramide has not yet been systematically assessed regarding its possible impact on GMA (This assertion is based on Pub Med [http://www.ncbi.nlm. nih.gov/pubmed/] search result for the product of logical term metoclopramide and the sum of logical terms: electrogastrography, gastric myoelectric* activity, gastric slow waves, gastric pacesetter).

2. Domperidone (not available in Poland, but quite popular in other Western countries as an oral medication called Motilium) is a drug of similar action to metoclopramide. It has an affinity for the same D2 receptor, but with greater selectivity for the gastrointestinal tract, which reduces the risk of side effects. The EGG studies have shown that in patients with diabetic gastroparesis and dysrhythmia (i.e. with a relatively considerable presence of bradygastria and/or tachygastria in the electrogastrogram), the administration of domperidone normalises GMA in some patients, restoring the presence of slow waves with a frequency of approximately $3 \mathrm{cpm}$ (cycles per minute) [3]. In children with type 1 diabetes and gastroparesis, domperidone seems to be even more effective than cisapride [4].

3. Itopride, newly introduced to the Polish market and previously registered in other countries, does not appear to have the disadvantages of metoclopramide, and it is more sophisticated than domperidone. This dopaminergic D2 receptor antagonist does not have the ability to cross the blood-brain barrier, as well as demonstrating acetylcholinesterase inhibitor activity. Due to these pharmacological properties, it is an effective prokinetic drug [5]. Two-week itopride treatment of patients with non-ulcer dyspepsia resulted in a significant increase in the relative time share of normogastria in the EGG reading and accelerated gastric emptying (Otsuba, et al. - cited by [5]).

4. Erythromycin is a macrolide antibiotic with relatively recently discovered additional agonist properties towards motilin receptors. The result of this action is an increase in the strength of contractions of the gastric antrum and the appearance of motor activity similar to the third phase of the migrating motor complex (MMC), and hence the acceleration of gastric emptying and activation of propulsive motility. Interestingly, the positive effect of erythromycin on the GMA and the motility of the antrum is detectable even at amounts lower than the standard doses, when used as an antibiotic. This effect, in children, has been demonstrated at a dose of $3 \mathrm{mg} / \mathrm{kg}$ body weight [6]. In adults, a single dose of $50 \mathrm{mg}$ of erythromycin, administered as 20-minute intravenous infusion, resulted in a slightly shorter (by approximately $17 \%$ ) halftime of gastric empting of solid food in comparison with placebo treatment. Increasing the dose to $100 \mathrm{mg}$ of erythromycin did not improve this effect [7]. Remarkably, following further application of erythromycin, deterioration of GMA in the postprandial period was observed - the relative normogastria time-share was reduced, and the tachygastria proportion increased. In addition, the frequency of dominant gastric slow waves decreased and the instability factor (dominant frequency instability coefficient - DFIC) significantly increased [7]

Unquestionably, the antibacterial activity of erythromycin causes restrictions in its use as a prokinetic drug, but it is still suitable for short-term use for this purpose under hospital conditions. Erythromycin, as a drug stimulating gastric and intestinal motility, is recommended especially in emergency situations, for example: the intestinal atony, or in conditions requiring rapid gastric emptying, such as with the need of carrying out urgent endoscopy due to upper gastrointestinal tract bleeding.

5. Many clinical trials evaluating the effects of prokinetic treatment in patients with gastroparesis have been performed using cisapride. It is agonist drug of the serotonin receptortype $4\left(5-\mathrm{HT}_{4}\right)$. The result of this action is an increased release of acetylcholine from the nerve endings in the gastrointestinal tract and thereby increasing the tension of the lower oesophageal sphincter (antireflux action). In addition, it increases the amplitude of the propulsive waves in the stomach and duodenum (prokinetic effect). A limitation for its use is the interaction with several other medications 
owing to adverse effects on cardiac function - by action of lengthening the period of ventricular repolarisation, which manifests on ECG by QT segment prolongation, with an increased risk of serious ventricular arrhythmias. Nevertheless, after taking into consideration contraindications to its use and potential risks of polypragmasy, cisapride is still a valuable therapeutic drug.

Cisapride, used in patients with impaired gastric emptying, removes the clinical symptoms and improves the rate of gastric evacuation. The beneficial clinical effect of cisapride is associated with normalisation of ailments detected in the EGG record [8]. As shown by Chang et al. [9], the increased presence of tachygastria in the electrogastrogram of patients with idiopathic or diabetic gastroparesis is significantly reduced after use of cisapride. Similar observations have been made in paediatric cases [10].

For many years there has been on-going research into new active substances with qualities similar to cisapride, i.e. of a selective $5-\mathrm{HT}_{4}$ receptor agonist, but deprived of its original side effects on the circulatory system. An example of such a new drug is mosapride, which, in studies on healthy volunteers, significantly accelerated gastric emptying. It has been shown that, without changing the dominant frequency of gastric slow waves, it has significantly increased their amplitude in the original EGG record [11].

6. Proton pump inhibitors (PPI) are among the most commonly used drugs in gastroenterology. The main indications for their use are: gastroesophageal reflux disease (GERD), functional dyspepsia, peptic ulcer disease and eradication of Helicobacter pylori. Myoelectrical gastric dysfunction has been reported in these diseases, with a positive effect of empirical PPI treatment. There are reports that correlate the clinical improvement in the upper gastrointestinal tract diseases with an improvement in the EGG record after PPI application. Chang et al. [12] reported a significant reduction in the relative time contribution of bradygastria and increased normogastria share in the postprandial period in patients with GERD after 4 weeks of treatment with 20 mg of omeprazole p.o. However, studies on healthy volunteers did not demonstrate a significant effect on the GMA, or the rate of gastric emptying of semi-solids, after a 7-day application of $20 \mathrm{mg}$ of omeprazole p.o. [13].

Another representative of the PPI group is rabeprazole, administered to healthy volunteers for a week at a dose of $20 \mathrm{mg}$ p.o., which had no effect on the EGG record performed during the maximum oral water load test [14]. However, Chen et al. [15] demonstrated that eight weeks of treatment with esomeprazole resulted in a minor, but statistically significant, increase in the relative time contribution of normogastria in patients with GERD.

\section{Changes in the EGG record due to medication for reasons other than gastrological}

Progress in the prevention and treatment of chronic diseases, has resulted in the life expectancy in Poland to increase each year. Therefore, an increasing proportion of people use prolonged pharmacotherapy, often with combinations of different drugs. The consequences are relatively common undesirable side effects of chronic drug use, and decreased quality of life. The most common side effects are gastrointestinal tract disorders, including those of the stomach. Drugs that have proven to affect the gastric myoelectrical activity include the following:

\section{Antidepressants}

One of the best-known and most often used antidepressants is fluoxetine. Wu et al. [16] reported in EGG traces that patients with functional dyspepsia and depression had significantly lower relative time proportion of normogastria, both in fasting and postprandial periods. At the same time, the relative time proportion of tachygastria increased in this group of patients. Treatment with fluoxetine with a dose of $20 \mathrm{mg}$ daily for 1 month caused a decrease in DFIC, but there was no significant drop in the relative time-share of tachygastria in electrogastrograms [16]. Doxepin, in a single oral dose of $25 \mathrm{mg}$, significantly reduced the meal-evoked ries of the dominant power of gastric slow waves in healthy volunteers [17].

\section{Drugs acting on the autonomic system}

Non-selective cholinergic agonist substances, such as edrophonium, have strong stimulating gastric motility properties. The influence of this drug on the EGG record mainly relates to increasing the amplitude of the dominant slow wave rhythm without changes in dominant frequency [18]. Anti-cholinergic drugs, such as scopolamine, have the opposite effect, as they reduce the amplitude of gastric slow waves in an electrogastrogram, but at the same time an increase in the frequency of dominant waves is observed [19].

A case report indicates that cevimeline, a selective muscarinic $M 3$ receptor agonist, applied for the symptomatic treatment of dryness of conjunctiva of eyes and mucosa of the mouth in Sjögren's syndrome, may increase the dominant frequency of gastric slow waves, especially during the interdigestive period [20]. 


\section{(Neuro)hormones and hormonal drugs}

Motilin administered by intravenous infusion, despite the stimulating motility effect on the gastric antrum, did not elicit perceptible changes in the EGG record of GMA in healthy volunteers [21]. Intravenous infusion of cholecystokinin octapeptide (CCK-8) resulted in a decrease dominant power of gastric slow waves in the postprandial period, without changing their dominant frequency [22].

Glucagon, like scopolamine, decreased the amplitude of gastric slow waves in an electrogastrogram while increasing their dominant frequency [19].

Calcitonin - a drug that strongly delays stomach evacuation [23] - administered intranasally, reduced the relative time share of bradygastria, but did not significantly affect the contribution of normogastria in postprandial electrogastrogram [24].

In pharmacological doses, vasopressin is an exemplary drug causing bradygastria [25].

\section{Cardiac medications}

Nitrates have significant effects on GMA. Although the dominant frequency of gastric slow waves was not altered after 1 week of treatment with isosorbide dinitrate, a significant reduction was observed in meal-evoked signal amplitude increase on electrogastrogram [26].

\section{Drugs used in anaesthesia}

The main indication for the use of naloxone is to reverse the effects of opioids, for example in narcotic agent intoxication or awaking from sedation after anaesthesia. Naloxone is also a drug that is sometimes used in situations very different from its main indications. It was found, for example, that it can be effective in cases of aggravating itchiness in liver disorders with cholestasis. Naloxone has the ability to accelerate intestinal transit time with partial normalisation of the electrogastrographic record, as demonstrated in the case of gastrointestinal pseudo-obstruction [27]. A study done with healthy volunteers did not show any significant effect of naloxone on GMA, or on the rate of gastric emptying [28].

Another drug often used in anaesthesia with documented significant effect on the myoelectric activity of the stomach is fentanyl, a painkiller drug belonging to the family of opioid analgesics. Approximately half of the patients undergoing anaesthesia with fentanyl showed a significant decrease in both the dominant frequency and dominant power in the electrogastrographic record [29].

\section{Stimulants}

Alcohol, cigarettes (containing nicotine), and coffee (due to the caffeine content) are the most common stim- ulants used in European countries. Each of these substances has a documented strong effect on the human body, including actions potentially disrupting the GMA.

Ethyl alcohol is a substance with a proven effect on motility of the upper gastrointestinal tract. Most of the work evaluating the effect of alcohol on myoelectrical activity and gastric emptying suggest that consumption of ethanol delays gastric emptying [30]. Pfaffenbach et al. [31] showed that, in comparison to healthy subjects, GMA in alcoholics was characterised by a relatively lower time-share of bradygastria. On the other hand, in conditions of acute exposure, Levanon et al. [32] observed a significant decrease in dominant power of gastric slow waves after consumption of white wine with $12.5 \%$ volume ethanol content. However, Turkish researchers found that orange juice with $40 \%$ volume ethanol content did not significantly modify any of the evaluated electrogastrographic parameters [33]. In a recent study, Kasicka-Jonderko et al. [30] showed that the influence of alcoholic beverages on GMA depends on ethanol concentration. Whisky and an aqueous solution of ethanol with the same concentration of $43.5 \%$ volume significantly impaired the dominant power of the gastric slow waves in the electrogastrographic GMA record. However, neither red wine (13.7\% vol.) nor beer (4.7\% vol.) nor aqueous ethanol solutions of the corresponding concentrations exerted a noticeable effect on the GMA [30].

Nicotine administered in a controlled manner via transdermal patches resulted in a significant impairment of GMA. In the study on non-smoking volunteers, administration of $14 \mathrm{mg}$ of nicotine caused an increase in the relative time-share of tachygastria, from an average of $2 \%$ to as much as $16 \%$, and an increase in DFIC. Electrogastrographic disturbances were accompanied by severe nausea [34]. Transdermal application of nicotine in the same dose of $14 \mathrm{mg}$ did not cause any problems on GMA in heavy smokers [34]. Under conditions of acute exposure, smoking of 2 cigarettes of nominal nicotine content of $1 \mathrm{mg} /$ piece did not cause definite changes in GMA during the postprandial period in heavy smokers [35].

Animal studies have shown that the main effect of caffeine is an increase in contractile activity of the colon, and not the stomach [36]. In a pilot study with healthy volunteers, there was no significant effect on the GMA of $4 \mathrm{mg} / \mathrm{kg}$ of caffeine administered in grapefruit juice [37].

\section{Other substances}

Comparable to the properties of some drugs, certain substances present in food, or in the form of so-called dietary supplements, also have an effect on the GMA record. An example is ginger, a rhizome with a specific 
odour and a characteristic pungent taste. In folk medicine, it is a known herbal medication with antiemetic, antiseptic and stimulating properties. Research has shown that ginger administered prophylactically significantly reduces the severity of both subjective symptoms, and objective changes in the electrogastrographic record associated with motion sickness [25].

\section{Conclusions}

The intention of the authors was to acquaint the readers with a complete overview of the effects of drugs and stimulants on the GMA. This is a significant issue, particularly for physicians performing and interpreting EGG tests. It is also of importance to practitioners carrying out pharmacotherapy aimed at normalisation of GMA associated with functional gastrointestinal disorders, and a number of organic diseases within and beyond the digestive system. The examinations mentioned in this article were performed using a single-channel electrogastrographic recording system. We hope that the knowledge of the pharmacological modulation of GMA will soon be enriched by studies performed using newly available multichannel EGG, whose significant advantage over traditional methods is the registration of slow wave propagation in the stomach [38], possibly resulting in significantly deepening our understanding of the pharmacological impact on the GMA and... thus requiring further updating of this article.

\section{References}

1. Koch KL. Electrogastrography In: Schuster atlas of gastrointestinal motility in health and disease. Schuster MV, Crowell MD, Koch KL (eds.) Hamilton, BC Becker Inc. 2002; 185201.

2. Rao AS, Camilleri M. Metoclopramide and tardive dyskinesia. Aliment Pharmacol Ther 2010; 31: 11-9.

3. Koch KL, Stern RM, Stewart WR, et al. Gastric emptying and gastric myoelectrical activity in patients with diabetic gastroparesis: effect of long-term domperidone treatment. Am J Gastroenterol 1989; 84: 1069-75.

4. Franzese A, Borrelli O, Corrado G, et al. Domperidone is more effective than cisapride in children with diabetic gastroparesis. Aliment Pharmacol Ther 2002; 16: 951-7.

5. Chojnacki J. Itopride in the treatment of kinetic disorders of gastrointestinal tract [Polish]. Prz Gastroenterol 2011; 6: 139-45.

6. Faure C, Parys Wolff V, Navarro J. Effect of meal and intravenous erythromycin on manometric and electrogastrographic measurements of gastric motor and electrical activity. Dig Dis Sci 2000; 45: 525-8.

7. DiBaise JK, Park FL, Lyden E, et al. Effects of low doses of erythromycin on the $13 \mathrm{C}$ spirulina platensis gastric emptying breath test and electrogastrogram: a controlled study in healthy volunteers. Am J Gastroenterol 2001; 96: 2041-50.
8. Rothstein RD, Alavi A, Reynolds JC. Electrogastrography in patients with gastroparesis and effect of logn-term cisapride. Dig Dis Sci 1993; 38: 1518-24.

9. Chang CS, Lien HC, Yeh HZ, et al. Effects of cisapride on gastric dysrhythmia and emptying of indigestible solids in type-II diabetic patients. Scand J Gastroenterol 1998; 33: 600-4.

10. Cucchiara S, Minella R, Riezzo G, et al. Reversal of gastric electrical dysrhythmias by cisapride in children with functional dyspepsia. Report of three cases. Dig Dis Sci 1992; 37: 1136-40.

11. Endo J, Nomura M, Morishita S, et al. Influence of mosapride citrate on gastric motility and autonomic nervous function: evaluation by spectral analyses of heart rate and blood pressure variabilities, and by electrogastrography. J Gastroenterol 2002; 37: 888-95.

12. Chang FY, Lu CL, Chen CY, et al. Stomach myoelectrical response of patients with gastroesophageal reflux disease receiving omeprazole treatment. J Gastroenterol Hepatol 2003; 18: 1399-406.

13. Kamiya T, Shikano M, Tanaka M, et al. The effect of omeprazole on gastric myoelectrical activity and emptying. J Smooth Muscle Res 2011; 47: 79-87.

14. Jones MP, Shah D, Ebert CC. Effects of rabeprazol sodium on gastric emptying, electrogastrography, and fullness. Dig Dis Sci 2003; 48: 69-73.

15. Chen CL, Yi CH, Kuo TB, et al. Effect of acid suppression on gastric myoelectrical activity in GERD. Hepatogastroenterology 2008; 55: 1353-5.

16. Wu CY, Chou LT, Chen HP, et al. Effect of fluoxetine on symptoms and gastric dysrhytmia in patients with functional dyspepsia. Hepatogastroenterology 2003; 50: 278-83.

17. Jonderko K, Kotuła I, Kasicka-Jonderko A, et al. Dichotomy between the effects of doxepine on gastric myoelectrical activity and gastric emptying in humans (abstract). Gut 2002; 51 (Suppl III): A317.

18. Bonapace ES, Parkman HP, Fisher RS. Edrophonium provocative testing during electrogastrography (EGG). Effects on dyspeptic symptoms and the EGG. Dig Dis Sci 1998; 43: 1494-500.

19. Katoh K, Nomura M, Iga A, et al. Comparison of gastric peristalsis inhibition by scopolamine butylbromide and glucagon: evaluation by electrogastrography and analysis of heart rate variability. J Gastroenterol 2003; 38: 629-35.

20. Chiba T, Kudara N, Sato M, et al. Effect of a muscarinic M3 receptor agonist on gastric motility. J Gastroenterol Hepatol 2007; 22: 2039-41.

21. Kamerling IM, Van Haarst AD, Burggraaf J, et al. Dose-related effects of motilin on proximal gastrointestinal motilit. Aliment Pharmacol Ther 2002; 16: 129-35.

22. Chen JD, Lin ZY, Parolisi S, et al. Inhibitory effects of cholecystokinin on postprandial gastric myoelectrical activity. Dig Dis Sci 1995; 40: 2614-22.

23. Jonderko G, Gołąb T, Jonderko K. Calcitonin suppresses gastric emptying of a radiolabelled solid meal in humans. Br J Clin Pharmacol 1987; 24: 103-5.

24. Jonderko K, Pless E, Stefanik W, et al. Gastric motor safety of intranasal calcitonin (abstract). Gut 2002; 51 (Suppl III): A136.

25. Lien HC, Sun WM, Chen YH, et al. Effects of ginger on motion sickness and gastric slow-wave dysrhytmias induced by cir- 
cular vection. Am J Physiol Gastrointest Liver Physiol 2003; 284: G481-9.

26. Nomura M, Uehara K, Harada K, et al. Impairment of gastrointestinal motility by nitrate administration: evaluation based on electrogastrographic changes and autonomic nerve activity. Aliment Pharmacol Ther 2004; 20 Suppl 1: 118-24.

27. Schang JC, Devroede G. Beneficial effects of naloxone in a patient with intestinal pseudoobstruction. Am J Gastroenterol 1985; 80: 407-11.

28. Reber PU, Netzer P, Gaia C, et al. Influence of naloxone on gastric emptying of solid meals, myoelectrical gastric activity and blood hormone levels in young healthy volunteers. Neurogastroent Motil 2002; 14: 487-93.

29. Walldén J, Lindberg G, Sandin M, et al. Effects of fentanyl on gastric myoelectrical activity: a possible association with polymorphisms of the micro-opioid receptor gene? Acta Anaesthesiol Scand 2008; 52: 708-15.

30. Kasicka-Jonderko A, Jonderko K, Bożek M, et al. Potent inhibitory effect of alcoholic beverages upon gastrointestinal passage of food and gallbladder emptying. J Gastroenterol 2013; 48: 1311-23.

31. Pfaffenbach B, Adamek RJ, Hagemann D, et al. Gastric emptying and antral myoelectrical activity in chronic alcoholics with dyspepsia. Hepatogastroenterology 1998; 45: 1165-71.

32. Levanon D, Goss B, Chen JD. Inhibitory effect of white wine on gastric myoelectrical activity and the role of vagal tone. Dig Dis Sci 2002; 47: 2500-5.

33. Celebi Kobak A, Bor S. The acute effect of oral ethanol intake on gastric myoelectrical activity in healthy volunteers. Turk J Gastroenterol 2007; 18: 221-4.

34. Kohagen KR, Kim MS, McDonnell WM, et al. Nicotine effects on prostaglandin-dependent gastric slow wave rhytmicity and antral motility in nonsmokers and smokers. Gastroenterology 1996; 110: 3-11.

35. Jonderko K, Chabińska I, Błońska-Fajfrowska B. Effect of cigarette smoking on interdigestive gastric myoelectrical activity in humans. In: Neurogastroenterology - Falk Symposium 112 (ed.: MV Singer, HJ Krammer), Kluwer Academic Publishers, Dordrecht/Boston/London 2000; 520-4.

36. Abo M, Kono T, Lu CL, et al. Effect of caffeine on gastrointestinal myoelectric activity and colonic spike activity in dogs. Scand J Gastroenterol 2000; 35: 368-74.

37. Jonderko K, Arsan K, Golda P, et al. Effect of caffeine on gastric myoelectrical activity in humans (abstract). Neurogastroent Motil 2001; 13: 267.

38. Krusiec-Świdergoł B, Jonderko K, Pudełko $M$, et al. The past and the present of electrogastrography - advancement of the method [Polish]. Ann Acad Med Siles 2007; 61: 352-8.

Received: $\quad 21.11 .2011$

Accepted: $\quad 16.10 .2012$ 